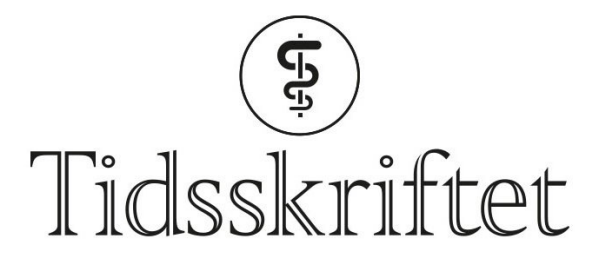

DEN NORSKE LEGEFORENING

\title{
Vanndampbehandling versus stripping av vena saphena magna ved åreknuter
}

ORIGINALARTIKKEL

ANNE-KATRINE LISLEGAARD NAES

Kirurgisk klinikk

St. Olavs hospital

Hun har bidratt med idé, utforming av studien, datainnsamling, analyse, tolkning, litteratursøk, og utarbeiding og godkjenning av manus.

Anne-Katrine Lislegaard Næs er master i klinisk helsevitenskap og sykepleier ved Kirurgisk klinikk, St. Olavs hospital.

Forfatteren har fylt ut ICMJE-skjemaet og oppgir ingen interessekonflikter.

\section{VIDAR HALSTEINLI}

Regionalt senter for helsetjenesteutvikling

St. Olavs hospital

og

Institutt for samfunnsmedisin og sykepleie

Norges teknisk-naturvitenskapelige universitet

Han har bidratt med idé, utforming av studien, analyse, tolkning, litteratursøk, og revisjon og godkjenning av manus.

Vidar Halsteinli er ph.d., helseøkonom og forsker ved St. Olavs hospital, og førsteamanuensis ved Institutt for samfunnsmedisin og sykepleie, NTNU.

Forfatteren har fylt ut ICMJE-skjemaet og oppgir ingen interessekonflikter.

\section{ARNE SETERNES}

E-post: arne.seternes@stolav.no

Karkirurgisk seksjon

Kirurgisk klinikk

St. Olavs hospital

og

Institutt for sirkulasjon og bildediagnostikk

Norges teknisk-naturvitenskapelige universitet

Han har bidratt med idé, utforming av studien, analyse, tolkning, litteratursøk, og utarbeiding, revisjon og godkjenning av manus.

Arne Seternes er ph.d., spesialist i generell kirurgi, gastrokirurgi og karkirurgi, overlege ved Karkirurgisk seksjon, St. Olavs hospital, og forsker ved Institutt for sirkulasjon og bildediagnostikk, NTNU.

Forfatteren har fylt ut ICMJE-skjemaet og oppgir ingen interessekonflikter. 


\section{BAKGRUNN}

Bruk av ny teknologi kan medføre endring i pasientforløp og behandlingskostnader for helsevesenet. Formålet med denne studien var å sammenligne sykefravær og tid frem til gjenopptatt dagligdags aktivitet samt behandlingskostnader ved to operasjonsmetoder for åreknuter: endovenøs dampbehandling og stripping.

\section{MATERIALE OG METODE}

Denne prospektive observasjonsstudien inkluderte 46 pasienter behandlet med dampablasjon og 37 behandlet med stripping i perioden 2015-2016. De to gruppene var like mht. alder, kjønn, arbeidssituasjon og klassifikasjon. Etter behandling ble pasientene intervjuet hver andre uke inntil dagligdagse aktiviteter var gjenopptatt. Detaljerte opplysninger om utgifter til personell, utstyr, lokaler og materiell ble brukt for å beregne behandlingskostnad.

\section{RESULTATER}

Pasienter behandlet med dampablasjon gjenopptok dagligdagse aktiviteter etter median $\mathrm{o}$ (interkvartilbredde o-2) dager mot 4 (2-7) dager for stripping ( $\mathrm{p}<0,001)$, og sportslige aktiviteter etter $4(2-9)$ dager mot 11 (3-19) dager $(\mathrm{p}<0,004)$. Hos pasienter $\mathrm{i}$ arbeid var sykefravær etter vanndampbehandling 2 (2-5) dager mot 14 (6-21) hos pasienter behandlet med stripping $(\mathrm{p}<\mathrm{o}, \mathrm{oo1})$. Beregnet behandlingskostnad for dampablasjon var 5973 kroner mot 10109 kroner for stripping.

\section{FORTOLKNING}

Dampablasjon førte til kortere rekonvalesens og sykefravær for pasienten, og lavere kostnad for sykehuset. Redusert sykefravær indikerer også lavere kostnad for samfunnet.

Åreknuter i bena er et vanlig helseproblem med en prevalens på over 20 \% i den voksne befolkningen. Årsaken er svikt i klaffefunksjonen i det overflatiske, og eventuelt det dype, venesystemet (1). Klaffesvikten fører til refluks og $ø$ kt trykk i det overflatiske venesystemet, med påfølgende dilatasjon og forlengelse av venen og åreknuter. Pasientene beskriver plager som smerte, tyngdefornemmelse, kløe, leggkramper og trette ben. Kronisk venøs svikt kan lede til delvis irreversible forandringer som eksem, pigmentering og sårdannelse. Kjønn, overvekt, antall graviditeter, alder, arv og etnisitet påvirker forekomsten (1, 2). I perioden 2003-2016 ble det registrert 95534 inngrep for åreknuter finansiert via det offentlige helsevesenet i Norge (3).

Målet med behandlingen er å oppheve overflatisk venerefluks og fjerne åreknutene. Vanlige behandlingsmetoder er stripping via lyskesnitt eller endovenøs ablasjon. Med sistnevnte metode destrueres åren termisk eller kjemisk. Energikilder som damp, laser eller radiofrekvens benyttes; ved kjemisk destruksjon brukes skum eller lim. Stripping gjøres oftest i regional eller generell anestesi $(1,4)$. Endovenøs ablasjon gjøres oftest i lokalbedøvelse og kommer like godt ut som stripping mht. klinisk resultat $(5,6)$. Ved St. Olavs hospital har stripping vært standardtilbudet, men fra 2013 ble poliklinisk dampbehandling introdusert. Selv om nye behandlingsmetoder kan kreve større utstyrsinvesteringer for klinikkene, kan slike investeringer redusere behandlingskostnadene. Det nasjonale systemet Nye metoder legger opp til at både effekt og kostnader bør være vurdert før nye metoder tas i bruk (7). Sykehusets kostnader er viktig, men det kan også være av interesse å undersøke konsekvenser for sykefravær.

Formålet med denne studien var å sammenligne behandlingskostnad for poliklinisk endovenøs dampbehandling og dagkirurgisk stripping ved insuffisiens i vena saphena magna, og dernest å undersøke om det var forskjell mellom de to behandlingsmetodene med hensyn til hvor lang tid det gikk før pasientene hadde gjenopptatt normal aktivitet og 
var tilbake i arbeid.

\section{Materiale og metode}

Studien var en prospektiv observasjonsstudie i poliklinisk og dagkirurgisk setting ved to sykehus i samme helseregion, og inkluderte pasienter behandlet i perioden oktober 2015-oktober 2016. Endepunkter var tid frem til gjenopptagelse av dagligdagse aktiviteter og sykefravær. Prosjektet var ikke fremleggspliktig for Regionale komiteer for medisinsk og helsefaglig forskningsetikk (REK), og dispensasjon fra taushetsplikten ble gitt for å identifisere egnede pasienter via operasjonsplanlegger og pasientadministrativt program (REK midt 2015/1458). Alle over 18 år som var planlagt til stripping eller poliklinisk dampbehandling, ble fortløpende forespurt om deltakelse. Prosjektet medførte ikke endring i allokert behandling, da pasientene var søkt inn for behandling før studiestart, og behandlingsmetode ble bestemt av kirurgens erfaringsnivå og klinikkens kapasitet ved søknadstidspunkt. Behandlingsdata ble registrert, og to spørreskjema (se appendiks på tidsskriftet.no) ble utviklet med bakgrunn i tidligere utført undersøkelse (8). Del 1 av spørreskjemaet ble fylt ut ved inklusjonstidspunktet. Pasienten fikk del 2 om dagligdagse aktiviteter, sport og sykefravær med seg hjem, og ble telefonintervjuet i henhold til skjemaet hver fjortende dag inntil gjenopptatt preoperativt aktivitetsnivå.

Utvalgsstørrelsen ble beregnet til å være $28 \mathrm{i}$ hver gruppe på bakgrunn av målefaktoren sykefravær med ønsket teststyrke 8o\% og o,05 signifikansnivå (tosidig) (9). En forskjell på tre dager ble ansett som klinisk signifikant, og standardavviket ble satt til fire dager basert på en tilsvarende studie (10).

Dersom pasienten gjenopptok aktivitet på behandlingsdagen eller påfølgende dag, ble antall dager satt til null. For pasienter som ikke gjenopptok arbeid og aktivitet av andre årsaker enn åreknutebehandlingen, ble antall dager beregnet ut fra opplysninger om når de trodde de ville ha gått tilbake til jobb.

Data ble analysert i Microsoft Excel og IBM SPSS Statistics versjon 24 (Armonk, NY, USA). Gruppeforskjeller i utfallsmålene ble korrigert for behandlingssted, kjønn, alder og dikotom CEAP-skår (clinical-etiology-anatomy-pathophysiology, 3 eller høyere) ved bruk av multippel lineær regresjon, og bootstrap-baserte konfidensintervall ble beregnet. Sammenligning av kontinuerlige data mellom gruppene ble gjort med Mann-Whitney Utest eller Kruskal-Wallis-test på grunn av manglende normalfordeling. Kategoriske data ble undersøkt med khikvadrattest eller Fishers eksakte test.

Kostnader ble beregnet ut fra sykehusets perspektiv. Standardiserte behandlingskostnader for stripping og dampablasjon ble beregnet ut fra en mikro-kostnadstilnærming (11). Ved St. Olavs hospital gjennomførte vi før studiestart observasjonsdager på poliklinikk, overvåkingsenhet og operasjonsstue for å registrere medgått tid, personalressurser, standardenheter og inngrepskostnad samt andre enheter eller ressurser som inngikk i standard prosedyre. Standard operasjonsteam for stripping besto av to operasjonssykepleiere, en kirurg, en anestesilege og en anestesisykepleier, tilsvarende for dampbehandling var to sykepleiere og en kirurg. Vi beregnet gjennomsnittlig tidsforbruk for hver enkelt yrkesgruppe (før studiestart) ut fra informasjon fra 30 tidligere pasienter behandlet med stripping samt 53 pasienter som tidligere hadde fått utført dampbehandling. I lønnskostnader ble lønn pluss sosiale kostnader tatt med. Enhetskostnader ble hentet fra St. Olavs hospitals økonomisystemer.

\section{Resultater}

Av 86 inviterte pasienter samtykket 83 til deltakelse. Vanndampbehandling ble utført hos 46 pasienter, alle ved St. Olavs hospital. Stripping ble utført hos 37, hvorav 21 ble behandlet ved Molde sykehus og 16 ved St. Olavs hospital. Pasientkarakteristika er fremstilt i tabell 1. Det var ingen forskjell mellom behandlingsgruppene og behandlingssted med tanke på alder, kjønn, arbeidsstatus, utdanning eller CEAP-skår. 
Tabell 1

Karakteristika for pasienter behandlet med vanndamp eller stripping, fordelt på sykehus. Prosentandeler dersom annet ikke er angitt.

\begin{tabular}{|lccrr|}
\hline Karakteristika & Damp & \multicolumn{2}{c|}{ Stripping } & \\
\cline { 2 - 4 } & $\begin{array}{c}\text { St. Olavs } \\
\text { hospital } \\
(\mathbf{n}=\mathbf{4 6})\end{array}$ & $\begin{array}{c}\text { St. Olavs } \\
\text { hospital } \\
(\mathbf{n}=\mathbf{1 6})\end{array}$ & $\begin{array}{c}\text { Molde } \\
\text { sjukehus } \\
(\mathbf{n}=\mathbf{2 1})\end{array}$ & p-verdi \\
\hline $\begin{array}{l}\text { Alder, median } \\
\text { (interkvartilbredde) }\end{array}$ & $53,7(43-64)$ & $51,6(47-63)$ & $\begin{array}{r}48,3 \\
(42-64)\end{array}$ & $0,599^{1}$ \\
\hline Kvinner & 71,7 & 68,8 & 66,7 & $0,910^{2}$ \\
\hline I arbeid & 65,2 & 75,0 & 81,0 & $0,390^{2}$ \\
\hline CEAP-klassifikasjon $^{3}$ & & & & \\
\hline \multicolumn{1}{c}{ C2 } & 56,5 & 43,8 & 57,1 & $0,511^{2}$ \\
\hline C3-C6 & 43,5 & 56,2 & 42,9 & $0,645^{2}$ \\
\hline Høyere utdanning & 56,5 & 50,0 & 42,9 & $0,576^{2}$ \\
\hline
\end{tabular}

${ }^{1}$ Kruskal-Wallis-test

${ }^{2}$ Khikvadrattest

${ }^{3}$ Clinical-etiology-anatomy-pathophysiology, klinisk klassifikasjon av åreknuter

Pasienter som fikk dampbehandling, rapporterte 2 (o-3) dager med begrensninger i dagligdagse aktiviteter, mens pasienter behandlet med stripping rapporterte 10 (4-16) dager ( $\mathrm{p}<\mathrm{o}, \mathrm{oo1}$ ). Pasienter behandlet med damp gjenopptok dagligdagse og sportslige aktiviteter etter henholdsvis o (o-2) og 4 (2-9) dager, mot 4(2-7) og 11 (3-19) etter stripping $(\mathrm{p}<\mathrm{o}, \mathrm{O01})($ tabell 2).

\section{Tabell 2}

Selvrapportert tid frem til gjenopptatt dagligdagse og sportslige aktiviteter for pasienter behandlet med vanndamp eller stripping. Medianverdier (interkvartilbredde) dersom annet ikke er angitt.

\begin{tabular}{|lccrc|}
\hline Variabel & $\begin{array}{r}\text { Damp }(\mathbf{n}= \\
\mathbf{4 6})\end{array}$ & $\begin{array}{c}\text { Stripping } \\
(\mathbf{n}=37)\end{array}$ & $\begin{array}{r}\text { Differanse }^{1} \\
(\mathbf{9 5 \%} \text { KI })\end{array}$ & p-verdi \\
\hline $\begin{array}{l}\text { Antall dager til pasienten } \\
\text { gjenopptar dagligdagse } \\
\text { aktiviteter }\end{array}$ & $0(0-2)$ & $4(2-7)$ & $-4,1(-6,9$ til & $<0,001$ \\
\hline $\begin{array}{l}\text { Antall dager med begrensninger i } \\
\text { dagligdagse aktiviteter }\end{array}$ & $2(0-3)$ & $10(4-16)$ & $\begin{array}{r}-8,5(-13,2 \text { til } \\
-4,6)\end{array}$ & $<0,001$ \\
\hline $\begin{array}{l}\text { Antall dager til pasienten } \\
\text { gjenopptar sportslige aktiviteter }\end{array}$ & $4(2-9)$ & $11(3-19)$ & $\begin{array}{r}-5,1(-10,6 \text { til } \\
-0,6)\end{array}$ & 0,073 \\
\hline
\end{tabular}

${ }^{1}$ Differanse basert på multippel lineær regresjon, kontrollert for behandlingssted og alder, og med bootstrap-basert konfidensintervall og p-verdi.

30 av 46 dampbehandlede pasienter og 29 av 37 strippingbehandlede pasienter var i arbeid ved inklusjonstidspunktet. Pasienter behandlet med damp var tilbake i arbeid etter median 2 (2-5) dager, og pasienter behandlet med stripping var tilbake i arbeid etter 14 (6-21) dager ( $\mathrm{p}<$ o,001) (tabell 3). 22 av pasientene behandlet med damp rapporterte at de kunne ha vært tilbake på jobb tidligere enn antall dager med sykmelding, mot 12 av pasientene behandlet med stripping. Pasienter behandlet med damp oppga et behov for sykefravær på 1 (o-4) dag(er), mens pasienter behandlet med stripping oppga et behov for sykefravær på 14 (7-20) dager. To pasienter i gruppen behandlet med stripping gjenopptok ikke arbeid av andre 
årsaker enn behandlingen.

\section{Tabell 3}

Selvrapportert sykefravær og behov for sykefravær målt i dager. Pasienter i arbeid ved inklusjonstidspunkt behandlet med vanndamp eller stripping. Verdier oppgitt i median (interkvartilbredde). Differanse korrigert for sykehus, alder, kjønn og klassifikasjon.

\begin{tabular}{|lcccc|}
\hline Variabel & $\begin{array}{c}\text { Damp } \\
(\mathbf{n = 3 0})\end{array}$ & $\begin{array}{c}\text { Stripping } \\
(\mathbf{n = 2 9})\end{array}$ & $\begin{array}{c}\text { Differanse }^{\mathbf{1}} \\
(\mathbf{9 5} \% \mathbf{K I})\end{array}$ & p-verdi \\
\hline Sykefravær & $2(2-5)$ & $14(6-21)$ & $-10,6(-15,3$ til $-5,9)$ & $<0,001$ \\
\hline Kunne vært tilbake i arbeid & $0(0-4)$ & $12(4-20)$ & $-10,8(-15,8$ til $-5,9)$ & $<0,001$ \\
\hline Behov for sykefravær & $1(0-4)$ & $14(7-20)$ & $-11,2(-14,9$ til -7,9) & $<0,001$ \\
\hline
\end{tabular}

${ }^{1}$ Differanse basert på multippel lineær regresjon, kontrollert for sykehus, kjønn, alder og CEAP (clinical-etiology-anatomy-pathophysiology, klinisk klassifikasjon av åreknuter), og med bootstrap-basert konfidensintervall og p-verdi.

Behandlingskostnader er fremstilt i tabell 4. Våre beregninger viste at standard sykehuskostnad var 5973 kroner per inngrep ved dampbehandling og 10109 kroner per inngrep ved stripping, dvs. en kostnadsdifferanse på 4136 kroner. Den samlede personalkostnaden var 1638 kroner for dampbehandling og 5635 kroner for stripping. Forskjellen skyldtes bruk av personell knyttet til regional og generell anestesi ved stripping. I tillegg brukte operasjonssykepleiere 4,08 timer ved stripping, mens sykepleietiden ved dampbehandling var 2,48 timer. Kostnader til engangsutstyr var 3399 kroner for vanndamp, mot 1578 kroner for stripping. Forskjellen skyldtes prisen på dampkateteret. Kostnader til renhold og lokale var 1312 kroner for stripping og 550 kroner for vanndampbehandling. Kostnadsforskjeller for flergangsutstyr, medikamenter og mat kommer frem av tabell 4 .

\section{Tabell 4}

Beregnet kostnad per pasient behandlet med vanndamp eller stripping ved St. Olavs hospital, på grunnlag av kostnadsenheter som inngår, volum og enhetskostnad per volumenhet. Kostnadene er oppgitt i norske kroner (NOK) og følger 2015-prisnivå.

\begin{tabular}{|c|c|c|c|}
\hline \multirow{2}{*}{$\begin{array}{l}\text { Enheter som inngår } \\
\text { (måleenhet) }\end{array}$} & Volum/antall & Enhetskostnad & Beregnet kostnad \\
\hline & Vanndamp Stripping & Vanndamp Stripping & Vanndamp Stripping \\
\hline \multicolumn{4}{|l|}{ Personale } \\
\hline Sykepleier (timer) & 2,48 & 367 & 910 \\
\hline $\begin{array}{l}\text { Operasjonssykepleier } \\
\text { (timer) }\end{array}$ & 4,08 & 403 & 1644 \\
\hline $\begin{array}{l}\text { Anestesisykepleier } \\
\text { (timer) }\end{array}$ & 2,04 & 403 & 822 \\
\hline $\begin{array}{l}\text { Intensivsykepleier } \\
\text { (timer) }\end{array}$ & 2,54 & 403 & 1024 \\
\hline Kirurg (timer) & 1,29 & 644 & 728 \\
\hline Anestesilege (timer) & 2,04 & 644 & 1314 \\
\hline Sum personale & & & 5635 \\
\hline \multicolumn{4}{|l|}{ Engangsutstyr } \\
\hline Stripper (antall) & 1 & 118 & 118 \\
\hline $\begin{array}{l}\text { Vanndampkateter } \\
\text { (antall) }\end{array}$ & 1 & 2500 & 2500 \\
\hline $\begin{array}{l}\text { Strippingpakke } \\
\text { (antall) }\end{array}$ & 1 & 1460 & 1460 \\
\hline $\begin{array}{l}\text { Vanndamppakke } \\
\text { (antall) }\end{array}$ & 1 & 899 & 899 \\
\hline Sum engangsutstyr & & & 3399 \\
\hline
\end{tabular}




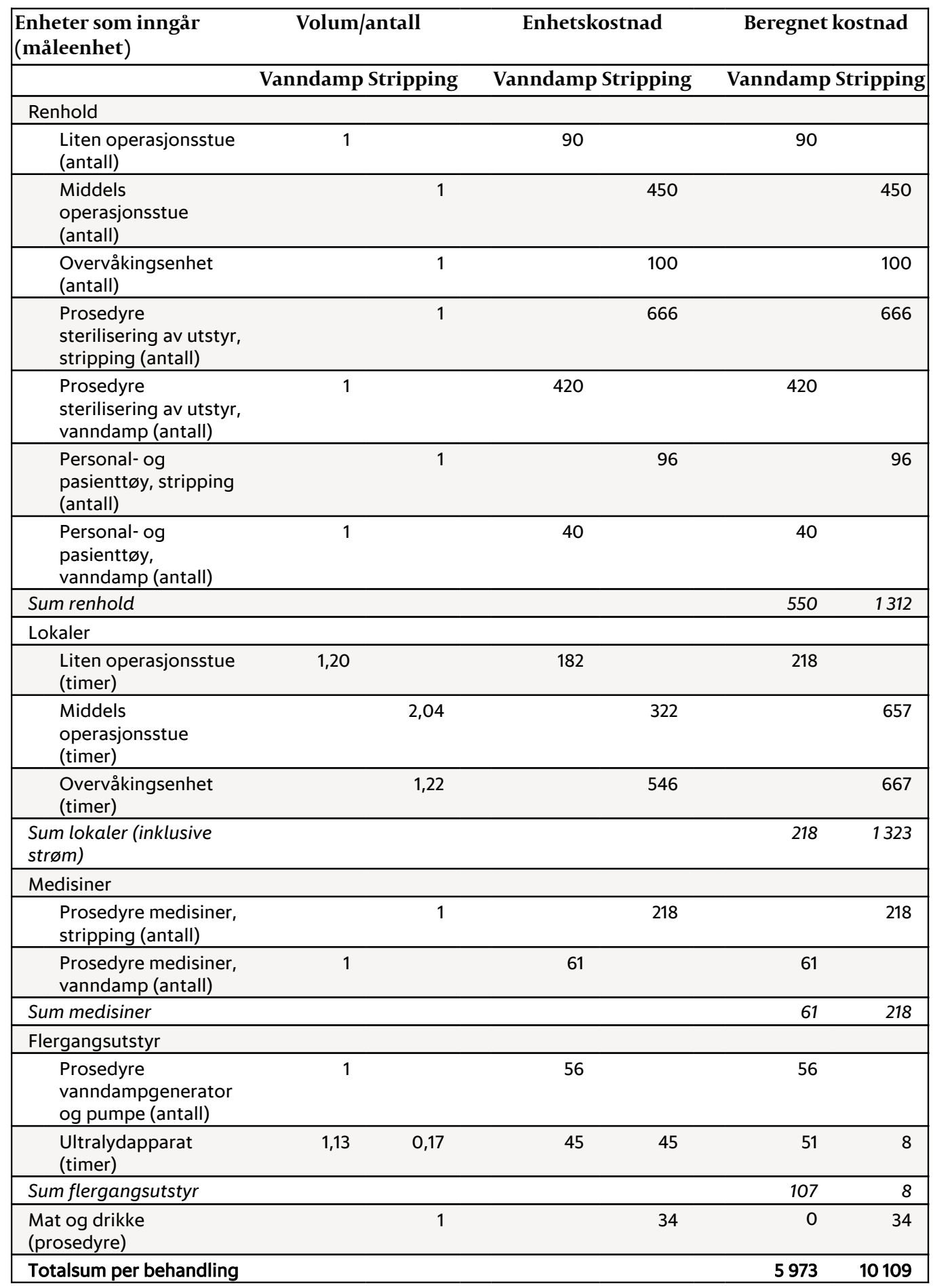

3 av 46 pasienter behandlet med damp og 11 av 37 behandlet med stripping rapporterte prosedyrerelaterte komplikasjoner.

\section{Diskusjon}

Våre beregninger viste at standard behandlingskostnad ved dampbehandling var lavere enn ved stripping. Dernest fant vi at damppasienter hadde lavere sykefravær, gjenopptok dagligdagse og sportslige aktiviteter tidligere, og opplevde færre dager med begrensninger i dagligdagse aktiviteter.

Vi har beregnet kostnader til personale og lokale ut fra tidsberegninger gjort i egen virksomhet. Behovet for utdanning av helsepersonell påvirker tidsbruken, og det er ikke alltid mulig å strømlinjeforme virksomheten slik en kan ved institusjoner som rapporterer kort prosedyretid ved stripping (6). Krav til opplæring av kirurger påvirker operasjonstiden, og vil derfor gi størst utslag for stripping, som involverer mest personell. Det har vi forsøkt å kompensere for ved at vi kun har regnet med én kirurg. Siden 
endovenøs dampbehandling er et nyetablert tilbud ved vår klinikk, kan det være at personalet ikke har nådd «toppen av læringskurven», og derfor bruker lengre tid på prosedyren. Lavere personalinnsats og kortere behandlingstid kan føre til at kostnaden knyttet til damp synker på sikt, noe som vil øke kostnadsdifferansen i favør av damp ytterligere. Tidsbruken ved vår institusjon vurderes som sammenlignbar med andre institusjoner både ved stripping og damp (6).

Vi fant høyere kostnader til engangsmateriell for damp enn stripping, noe som skyldes prisen på dampkateteret. I enkelte studier har denne kostnaden blitt utslagsgivende for hvilken behandlingsmetode som var billigst $(12,13)$.

Kostnader ble beregnet ved et standardisert inngrep, en metode som også har vært brukt tidligere (14). Registrering av ressursbruk ved hver operasjon ville ha gitt informasjon om variasjon i tidsbruk og kostnader, men var utenfor rammen for denne studien. Vi fant at damp hadde lavere behandlingskostnad enn stripping, men det er grunn til å tro at kostnaden kan variere ut fra lokale forhold knyttet til anestesi og operasjonsmetoder, lønnskostnader, organisering og allokering av personell. Dette kan være en forklaring på at en annen norsk studie kom ut med en noe lavere kostnad for stripping enn det vi gjorde (15).

Helsetjenestekostnader påløpt etter gjennomført behandling bør til vanlig tas i betraktning, men ble utelatt i vår studie, da rapportert behov for helsetjenester etter åreknutebehandling har vært lavt $(11,12)$. I vår studie ble det imidlertid rapportert flere prosedyrerelaterte plager og komplikasjoner for pasienter behandlet med stripping. I fremtidige kostnadsstudier av åreknutebehandling bør disse kostnadene inkluderes.

Vi definerte dagligdagse aktiviteter som enkle, personnære aktiviteter som av- og påkledning, mens andre har inkludert også mer komplekse aktiviteter som bilkjøring og barnepass (16). Vi fant at strippingbehandlede pasienter gjenopptok dagligdagse aktiviteter etter median fire dager og rapporterte begrensninger i dagligdagse aktiviteter i ti dager. Dampbehandlede pasienter gjenopptok dagligdagse aktiviteter ved første postoperative dag og rapporterte begrensninger i to dager, noe som er i tråd med andre studier (10, 17-19).

Våre pasienter behandlet med stripping hadde et median sykefravær på 14 dager. Andre har rapportert sykefravær fra 4 til 26 dager etter stripping, forskjeller som nok kan tilskrives både ulik sykelønnsordning, ulike forventninger i befolkningen og kirurgiske teknikker (10, 12, 13, 19-26). Våre dampbehandlede pasienter gjenopptok arbeid etter median 2 dager. Dette er en betydelig forskjell, med en differanse (ukorrigert) på 12 dager. Som illustrasjon kan 12 dager bety en samfunnsmessig besparelse på i størrelsesorden 27 ooo kroner dersom vi tar utgangspunkt i en årslønn på 518 ooo (27). En slik gevinst ville ha kommet i tillegg til den lavere sykehuskostnaden ved damp.

Studiedesignet uten randomisering og blinding gjør at vi ikke med sikkerhet kan utelukke at de observerte forskjellene i sykefravær og gjenopptagelse av aktiviteter skyldes andre, ukjente forhold, og utvalgsskjevhet kan ha forekommet siden vi inkluderte pasienter fortløpende. Resultatene må derfor tolkes i lys av dette. En styrke var likevel den strukturerte måten spørsmålene om dagligdagse aktiviteter, trening og sykefravær ble lest opp på, og dessuten det at pasientene var kjent med spørsmålene i forkant. Dette var likt for begge grupper.

Den korte oppfølgingstiden og den manglende målingen av klinisk effekt gjør at vi ikke kan si noe om det kliniske resultatet som sådan og eventuelt fremtidig behov for ny behandling, og dermed heller ikke noe om økonomiske forskjeller over tid. Resultatene fra en annen studie sannsynliggjør imidlertid at det kliniske resultatet ved stripping og damp er likt, og det er ikke rapportert statistisk signifikante forskjeller i tilbakefall (28).

En av styrkene ved vår studie er at alle pasienter som ble behandlet i en tidsperiode, fikk tilbud om å delta, og at kun tre sa nei. Pasientene ble fulgt opp tett, og vi oppnådde en svarprosent på 10o. Vi antar derfor at det er lav risiko for hukommelsesbias, oppfølgingsbias og frafallsbias (29). 
Det finnes generelt lite forskning på effekten av vanndampbehandling på kort og lang sikt, og det er behov for gode randomiserte kliniske undersøkelser. I en modellbasert studie ble også behov for bedre økonomiske data påpekt (15).

\section{HOVEDBUDSKAP}

Vanndampbehandling for åreknuter kostet mindre for sykehuset enn stripping

Vanndampbehandling innebar tidligere gjenopptakelse av dagligdagse aktiviteter

Vanndampbehandling innebar betydelig kortere sykefravær

\section{LITTERATUR:}

1. Gloviczki P, Comerota AJ, Dalsing MC et al. The care of patients with varicose veins and associated chronic venous diseases: clinical practice guidelines of the Society for Vascular Surgery and the American Venous Forum. J Vasc Surg 2011; 53: 2S-48S. [PubMed][CrossRef]

2. Wittens C, Davies AH, Bækgaard N et al. Editor's choice - Management of chronic venous disease: Clinical practice guidelines of the European Society for Vascular Surgery (ESVS). Eur J Vasc Endovasc Surg 2015; 49: 678-737. [PubMed][CrossRef]

3. Helsedirektoratet. Innsatsfinansiert styringsdata 2003-2016. https://helsedirektoratet.no/norsk-pasientregister-npr (3.1.2019).

4. Carroll C, Hummel S, Leaviss J et al. Systematic review, network meta-analysis and exploratory costeffectiveness model of randomized trials of minimally invasive techniques versus surgery for varicose veins. Br J Surg 2014; 101: 1040-52. [PubMed][CrossRef]

5. van den Bos R, Arends L, Kockaert M et al. Endovenous therapies of lower extremity varicosities: a meta-analysis. J Vasc Surg 2009; 49: 230-9. [PubMed][CrossRef]

6. Nesbitt C, Bedenis R, Bhattacharya V et al. Endovenous ablation (radiofrequency and laser) and foam sclerotherapy versus open surgery for great saphenous vein varices. Cochrane Database Syst Rev 2014; 7: CDoo5624. [PubMed]

7. Nye metoder. Metodevurderinger. https://nyemetoder.no/om-systemet/metodevurderinger (3.1.2019).

8. Foss L, Skyberg K. Sykefravær i ulike bransjer: utvikling i sykefravær og uførhet i lys av individuelle faktorer og forhold ved arbeidsplassen. STAMI-rapport nr. 18. Oslo: Statens arbeidsmiljøinstitutt, 2008. https://brage.bibsys.no/xmlui/bitstream/handle/11250/288544/stamirapporter_85.pdf?sequence=1\&isA llowedy (3.1.2019).

9. Aalen OO, Frigessi A, Moger TA et al. Statistiske metoder i medisin og helsefag. Oslo: Gyldendal akademisk, 2006.

10. Pronk P, Gauw SA, Mooij MC et al. Randomised controlled trial comparing sapheno-femoral ligation and stripping of the great saphenous vein with endovenous laser ablation ( $980 \mathrm{~nm}$ ) using local tumescent anaesthesia: one year results. Eur J Vasc Endovasc Surg 2010; 40: 649-56.

[PubMed][CrossRef]

11. Drummond MF, Sculpher MJ, Torrance GW et al. Methods for the economic evaluation of health care programmes. 3. utg. Oxford: Oxford University Press, 2005.

12. Subramonia S, Lees T. Radiofrequency ablation vs conventional surgery for varicose veins - a comparison of treatment costs in a randomised trial. Eur J Vasc Endovasc Surg 2010; 39: 104-11. [PubMed][CrossRef]

13. Rautio T, Ohinmaa A, Perälä J et al. Endovenous obliteration versus conventional stripping operation in the treatment of primary varicose veins: a randomized controlled trial with comparison of the costs. J Vasc Surg 2002; 35: 958-65. [PubMed][CrossRef]

14. Michaels JA, Campbell WB, Brazier JE et al. Randomised clinical trial, observational study and assessment of cost-effectiveness of the treatment of varicose veins (REACTIV trial). Health Technol 
Assess 20o6; 10: 1-196, iii-iv. [PubMed][CrossRef]

15. Inderhaug E. Costs and outcomes of five surgical treatments for great saphenous varicose veins; High Ligation and Stripping, Laser Ablation, Radiofrequency Ablation, Steam Vein Sclerosis and Cyanoacrylate Glue. Masteravhandling. Oslo: Universitetet i Oslo, 2014.

16. Cotton SC, MacLennan G, Brittenden J et al. Behavioural recovery after treatment for varicose veins. Br J Surg 2016; 103:374-81. [PubMed][CrossRef]

17. van den Bos RR, Proebstle TM. The state of the art of endothermal ablation. Lasers Med Sci 2014; 29: 387-92. [PubMed][CrossRef]

18. Mlosek RK, Woźniak W, Gruszecki L et al. The use of a novel method of endovenous steam ablation in treatment of great saphenous vein insufficiency: own experiences. Phlebology 2014; 29: 58-65. [PubMed][CrossRef]

19. Rasmussen LH, Lawaetz M, Bjoern L et al. Randomized clinical trial comparing endovenous laser ablation, radiofrequency ablation, foam sclerotherapy and surgical stripping for great saphenous varicose veins. Br J Surg 2011; 98:1079-87. [PubMed][CrossRef]

20. Helmy ElKaffas K, ElKashef O, ElBaz W. Great saphenous vein radiofrequency ablation versus standard stripping in the management of primary varicose veins-a randomized clinical trial. Angiology 2011; 62: 49-54. [PubMed][CrossRef]

21. Bountouroglou DG, Azzam M, Kakkos SK et al. Ultrasound-guided foam sclerotherapy combined with sapheno-femoral ligation compared to surgical treatment of varicose veins: early results of a randomised controlled trial. Eur J Vasc Endovasc Surg 2006; 31: 93-10o. [PubMed][CrossRef]

22. Vuylsteke M, Van den Bussche D, Audenaert EA et al. Endovenous laser obliteration for the treatment of primary varicose veins. Phlebology 2006; 21: 80-7. [CrossRef]

23. Carradice D, Mekako AI, Mazari FA et al. Randomized clinical trial of endovenous laser ablation compared with conventional surgery for great saphenous varicose veins. Br J Surg 2011; 98: 501-10. [PubMed][CrossRef]

24. Brittenden J, Cotton SC, Elders A et al. Clinical effectiveness and cost-effectiveness of foam sclerotherapy, endovenous laser ablation and surgery for varicose veins: results from the Comparison of LAser, Surgery and foam Sclerotherapy (CLASS) randomised controlled trial. Health Technol Assess 2015; 19: 1-342. [PubMed][CrossRef]

25. Darwood RJ, Theivacumar N, Dellagrammaticas D et al. Randomized clinical trial comparing endovenous laser ablation with surgery for the treatment of primary great saphenous varicose veins. Br J Surg 2008; 95: 294-301. [PubMed][CrossRef]

26. Eidson JL, Atkins MD, Bohannon WT et al. Economic and outcomes-based analysis of the care of symptomatic varicose veins. J Surg Res 2011; 168: 5-8. [PubMed][CrossRef]

27. Statistisk sentralbyrå. Lønn, alle ansatte 2015 .

https://www.ssb.no/statistikkbanken/selectvarval/saveselections.asp (3.1.2019).

28. Woźniak W, Mlosek RK, Ciostek P. Assessment of the efficacy and safety of steam vein sclerosis as compared to classic surgery in lower extremity varicose vein management. Wideochir Inne Tech Malo Inwazyjne 2015; 10: 15-24. [PubMed][CrossRef]

29. Portney LG, Watkins MP. Foundations of clinical research: applications to practice. Upper Saddle River, NJ: Prentice Hall, 2000.

Publisert: 6. mars 2019. Tidsskr Nor Legeforen. DOI: 10.4045/tidsskr.18.0525

Mottatt 18.6.2018, første revisjon innsendt 28.11.2018, godkjent 3.1.2019.

(C) Tidsskrift for Den norske legeforening 2020. Lastet ned fra tidsskriftet.no 